\title{
O PROCESSO DE ELABORAÇÃO COLABORATIVA DE PLANOS DE AULAS DE ESPANHOL NO ESTÁGIO SUPERVISIONADO
}

\section{THE PROCESS OF COLLABORATIVE ELABORATION OF SPANISH LESSON PLANS IN THE SUPERVISED INTEMSHIP}

\author{
Tânia Maria Diôgo do Nascimento (PPGLetras/UFPE) ${ }^{1}$ \\ Maria Cristina Damianovic (PPGLetras/UFPE) ${ }^{2}$
}

\section{RESUMO}

Esta comunicação visa discutir o papel da argumentação (LEITÃO, 2000), na prática da elaboração colaborativa (DIÔGO, 2015) de aulas de línguas estrangeiras, no processo de regência da disciplina de estágio supervisionado, na licenciatura em Letras. Alicerçada na metodologia da Pesquisa Crítica de Colaboração (MAGALHÃES, 2009). A análise inicial dos dados dessa pesquisa de doutorado revela que os discentes do Estágio Supervisionado expandem seus conhecimentos de forma internamente persuasiva (BAKHTIN, 1997) e constroem o conhecimento sobre a elaboração da aula de espanhol atribuindo-lhe novos valores, sentidos e significados.

PALAVRAS-CHAVE: Argumentação; Estágio Supervisionado/Letras Espanhol; Plano de Aula.

\begin{abstract}
This communication aims at discussing the role of argumentation (LEITÃO, 2000), in the practice of collaborative preparation of foreign language lessons, in the process of class regency of the supervised internship, in the Language Arts course. Based upon the methodology of Critical Collaborative Research (MAGALHÃES, 2009). Incipient data analysis in this doctoral research shows that supervised internship students expand their knowledge in an internally persuasive way (BAKHTIN, 1997) and construct knowledge about the Spanish lesson preparation, implying new values and meanings.
\end{abstract}

KEYWORDS: Argumentation; Supervised internship/ Language Arts Spanish; Lesson Plan.

\section{INTRODUÇÃO}

Ao lançarmos um olhar crítico-reflexivo sobre a licenciatura em Letras, com foco especial na disciplina de Estágio Supervisionado em Língua Espanhola, entendido como "um espaço de interlocução mútua entre os formadores, estagiários e professores colaboradores, não sendo mais visto apenas como um espaço de prática para futuros professores", (GIMENEZ e PEREIRA, 2007, P. 97), observamos um quase espaço vazio entre as vozes enunciativas que compõem este processo. Em termos de ensino-aprendizagem em sala de aula, nota-se que os professores e professoras de Estágio Supervisionado precisariam explorar a linguagem e a reflexão crítica que fazem da sala de aula uma práxis para o processo de ensino-aprendizagem de uma língua

\footnotetext{
${ }^{1}$ Doutoranda Letras/Linguística pelo PPGLetras da UFPE. Professora Titular do Curso de Letras da Faculdade LusoBrasileira - FALUB (Carpina-PE).diogotania@hotmail.com

2 É professora Adjunta IV no Departamento de Letras e no Programa de Pós-Graduação em Letras no Centro de Artes e Comunicação da Universidade Federal de Pernambuco. Ė coordenadora dos Grupos de Pesquisa LIGUE: Linguagem, Línguas, Escola e Ensino e LIFE: Literatura para a Vida. mcdamianovic@gmail.com
} 
estrangeira, como um instrumento-e-resultado, para um reposicionamento social e a construção de novas relações sociais, (LIBERALI, 2010).

Esta pesquisa pretende discutir como a construção crítico-colaborativa de planos de aula oferece aos alunos estagiários da disciplina de Prática de Ensino de fortalecerem seu conhecimento sobre a sala de aula, atribuindo-lhe novos valores, sentidos e significados, a partir da mediação do professor, de outros colegas e da sua performance de elaborar um plano de aula que lhe permite "ir mais além de si mesmo como outro", Liberali (2009). Como pedagogas críticas temos o desejo de transformar a realidade da graduação em Letras, em especial, da disciplina de Prática de Ensino, à luz de (RAJAGOPALAN, 2003, p.106):

O pedagogo crítico é, em outras palavras, um ativista, um militante, movido por certo idealismo e convicção inabalável de que, a partir da sua ação, por mais limitada e localizada que ela possa ser, seja possível desencadear mudanças sociais de grande envergadura e consequência.

Nesse cenário a presente pesquisa visa à formação crítico-colaborativa, (MAGALHÃES, 2006), do futuro professor de Língua Espanhola, na disciplina estágio supervisionado, na Licenciatura Letras/Espanhol, em uma faculdade privada no interior de Pernambuco.

A concepção de uma pesquisa de caráter intervencionista, (LIBERALI e LIBERALI, 2005), reflexivo-crítico-colaborativo (autor), e a visão de língua que aqui adotamos é a que a postula no conjunto dos aspectos históricos, profundamente sociais e carregada de ideologias. "A palavra está sempre carregada de um conteúdo ou de um sentido ideológico ou vivenvial" (BAKHTIN/ VOLOCHINOV, 1997, pg. 95).

Ao defendermos a língua como ideológica, na sua constituição sócio-histórico-cultural, nos inserimos no contexto enquanto sujeitos sócio-histórico-culturalmente constituídos e constituidores dos discursos diversos do nosso cotidiano. A língua é uma visão mais ampla de um ser social que se articula na vida dialogicamente, na construção de sentidos e de significados de forma compartilhada.

Nesse sentido é que nos inserimos e compreendemos a estrutura da enunciação na sua natureza profundamente social na comunicação discursiva, no que concerne à nossa responsividade (LIBERALI, 2012), como sujeitos situados historicamente, construindo e compartilhando saberes socialmente postos e transformando aspectos culturais na intervenção crítico-colaborativo.

Esta pesquisa tem como principal pilar teórico a TASHC - Teoria da Atividade Sócio-HistóricoCultural. Referenciando Vygotsky, Leontiev e Bakhtin, Liberali (2009, p. 19), elucida:

Na perspectiva sócio-histórico-cultural, os sujeitos constituem-se e aos demais nas relações com os objetos/mundo mediados pela sociedade. Esse processo de constituição de si, dos demais e da própria sociedade é de fundamental importância ao considerarmos a formação crítica de educadores. Para Vygotsky (1934), em suas práticas sociais, os sujeitos se engajam em atividades distintas e são essas atividades que propiciam oportunidades de desenvolvimento de si, dos outros e da sociedade. (In DIOGO, 2013, p. 33).

No Sendero da TASHC encontramos um relevante arcabouço teórico de Damianovic e Fuga (2010) para os estudos do ensino de línguas.. São achados que contribuem sobremaneira para a nossa pesquisa. Algumas reflexões subjacentes à questão em pauta nos dizem:

A atividade social tem nas questões bakhtinianas o seu alicerce, ao compreender que o outro é parte constitutiva do "eu", cuja relação acontece na e pela linguagem, considerada pelo Círculo de Bakhtin como constitutivamente dialógica. Como já dito, a atividade social destaca o caráter coletivo, social da produção de ideias e textos, excluindo qualquer possibilidade de um enfoque individualista. (DAMIANOVIC E FUGA, 2010, p. 179). 
Esta pesquisa é essencialmente coletiva, refutamos o enfoque individualista, corroboramos o constructo sócio-histórico-cultural como vetor de constituição imanente do ser humano. Somos constituídos pelos discursos de outrem, somos o lócus de interdependência crítico-colaborativo. O outro está em mim e eu estou no outro, logo, nesse "confronto" o nós estamos em constantes reflexões que permiti-nos as transformações necessárias.

Ainda na trilha das contribuições da Teoria da Atividade Sócio-Histórico-Cultural, acolhemos favoravelmente o pensamento de Diogo (2013):

Essas elucidações sobre a Teoria da Atividade Sócio-Histórico-Cultural, (doravante TASHC), posicionam a nossa atuação na esfera do ensino-aprendizagem da língua espanhola, porque defendemos o paradigma de ensino onde professores e alunos vão se constituindo colaborativamente, por meio das atividades sociais que a comunidade acadêmica, no nosso caso, da graduação em Letras/Espanhol, demandam. (DIOGO, 2013, p. 33).

Com o fim de elucidar a questão sobre a TASHC e assim situar melhor os nossos leitores, trazemos as contribuições de Larré (2014):

Na Teoria da Atividade Sócio-Histórico Cultural (TASHC), a perspectiva de cunho marxista, (...) é uma de suas bases e é fundamental que o pesquisador esteja consciente não só de seu papel como cientista, investigador, como também de seu papel no mundo social e nas necessidades desse mundo, considerando suas impressões mais pessoais e sobre como sua pesquisa influencia neste cosmos. É fazer a jornada de transformação, tendo constantemente como objeto a transformação do mundo ao nosso redor. (LARRÉ, 2014, p. 37).

A minha função como professora-pesquisadora vai além de mim, ela vai ao outro. O que vejo no meu entorno, o que penso disso, os posicionamentos que assumo, as contribuições que oferto, tudo isso me dizem e dizem ao outro quem sou e assim, estou plena do outro. Mas, quem é esse "outro", talvez o meu interlocutor questione... Para os nossos estudos atuais são os alunos do $6^{\circ}$ período da Licenciatura Letras/Espanhol da FALUB, os professores-colaboradores das escolas-campo de Estágio e os alunos das turmas observadas e posteriormente com aulas ministradas. As necessidades do mundo acadêmico estão em relação com as necessidades da Escola. O conhecimento construído colaborativamente e compartilhado de forma crítico-colaborativo é relacional porque agrega teoria e prática, sem dicotomias desnecessárias, antes com a sintonia positiva que influencia neste cosmo, no dizer sentido de Larré (2014).

Os nossos estudos estão inseridos nos pressupostos da Linguística Aplicada, doravante LA, Apoiamos as nossas discussões em (MOITA LOPES, 2006; PENNYCOOCK 2007; RAJAGOPALAN, 2003; DAMIANOVIC, 2005). Como "militante" pedagógica, tenho a LA como pilar teórico-metodológico no rumo da mudança dos tempos. Os ventos sopram e as transformações constituem a nossa práxis docente. Esses ventos dos câmbios necessários estão na constituição do nosso agir no mundo.

Como postula Moita Lopes (2006, p. 22, 23):

Vivemos tempos de grande ebulição sócio-cultural-político-histórica e epistemológica (...). São tempos em que os ideais da modernidade têm sido questionados e reescritos, principalmente aqueles referentes à definição do sujeito social como homogêneo, trazendo à tona seus atravessamentos identitários, construídos no discurso, como também os ideais que dizem respeito a formas de produzir conhecimento sobre tal sujeito (...).

Os novos tempos trazem consigo novos paradigmas para a sociedade moderna e nesse quadro, esses novos paradigmas inscrevem os modos de ser, pensar, agir e construir dos indivíduos, (DIOGO, 2013, p. 26). Defendemos a quebra de velhos paradigmas no ensino de línguas e queremos romper com 
o paradigma do ensino da língua espanhola, na questão focal da elaboração de planos de aula de forma crítico-colaborativo. A LA constitui uma disciplina que para a sociedade contemporânea representa a consolidação do diálogo entre teorias, levando a uma reconsideração dos modos de produzir conhecimento em ciências sociais (MOITA LOPES, 2006). nos inserimos:

Encontramos em Damianovic (2005), reflexões sobre o linguista aplicado e é nesse cenário que

\begin{abstract}
Nessa expansão de trabalho, o linguista aplicado iniciou pesquisas com um fundamento discursivo e sócio histórico. Como um ativista político, seu interesse hoje está em pesquisar problemas sobre os quais os estudos possam trazer mudanças para a realidade. O linguista aplicado do novo milênio preocupa-se com as óbvias e múltiplas iniquidades da sociedade e, por isso, está mais sensível às questões sociais, culturais e políticas. Ele começa a assumir projetos pedagógicos, políticos e morais para tentar propor saídas para problemas de linguagem no mundo real e mudar as circunstâncias de desigualdade. (DAMIANOVIC, 2005, p. 13).
\end{abstract}

Propor saídas para problemas de linguagem no mundo real e mudar as circunstâncias de desigualdade, o pensamento de Damianovic (2005) traz um fôlego leve, harmonioso, lúcido, coerente aos nossos estudos, mas, não menos instigante. Quero realizar mudanças significativas no cerne da minha comunidade acadêmica, a saber, a Faculdade Luso-Brasileira/FALUB. Sou ativista política quando me posiciono sócio-histórico-culturalmente e me rebelo com um paradigma que engessa no casulo das teorias monológicas. Quero dialogar com os meus pares. Quero propor o agir no mundo de forma distinta e comigo quero levar os partícipes dessas mudanças.

A língua espanhola está inserida nesse cosmos. O seu efetivo ensino clama por mudanças de paradigmas e por assumir o seu espaço no mundo. Ser um pesquisador, um ativista pedagógico ou mesmo político, requer a assunção de papeis e de posicionamentos, mas no agir crítico-colaborativo.

$\mathrm{Na}$ sequência das nossas reflexões, esboçamos algumas considerações que consideramos pertinentes sobre a língua espanhola no Brasil.

O ensino da Língua Espanhola no Brasil ganhou maior relevância quando da aprovação e consequente implantação da Lei $11.161 / 05^{3}$, que dispõe sobre a obrigatoriedade da oferta da língua espanhola nas escolas brasileiras, vieram consolidar um período de demandas distintas no ensino-aprendizagem de E/LE. Seja por seu caráter pedagógico, seja por fins acadêmicos, ou pelas relações internacionais, o fato é que o espanhol como língua estrangeira atravessa uma fase há tempos de auge e preferências por parte de estudantes, profissionais liberais e cidadãos brasileiros que buscam aprender ou aperfeiçoar este idioma. Nessa luta incessante pela continuidade do ensino da Língua espanhola nas escolas brasileiras, "milito" como professorespesquisadora, formadora de professores e designer de material didático (DIÔGO, 2015).

É inegável que a criação do bloco econômico do cone sul, MERCOSUL contribuiu e continua tendo a sua relevância nesse processo de ampliação da oferta de estudos do espanhol no Brasil. Outra consideração a ser feita é sobre a localização geográfica do Brasil, vizinho dos países que falam oficialmente o espanhol. Outros fatores não menos importantes são o número de falantes do idioma espanhol e os investimentos que a Espanha fez no Brasil nas últimas décadas. Podemos ilustrar os investimentos e iniciativas que movimentam o ensino da Língua Espanhola, através de alguns programas e projetos nacionais e internacionais de intercâmbios para alunos universitários e do Ensino Médio como o Programa Ciência sem Fronteiras, do Ministério da Educação e Cultura, o Programa Ganhe o Mundo, Núcleos de Estudos de Línguas, Programas do Governo do Estado de Pernambuco, Os CEL - Centros de Estudos de Línguas, Programa do Governo de São Paulo, as Becas MAE, Fundación Carolina e Erasmus, Programas do Governo Espanhol. As semelhanças existentes entre o Português e o Espanhol é outro fator que insere a Língua Espanhola depois do inglês, no ranking de segunda língua

\footnotetext{
${ }^{3}$ Apesar da atual revogação da Lei 11.165/05 pelo Governo Federal, continuo a acreditar e a trabalhar em prol do Ensino e da Aprendizagem da língua espanhola nos cursos de Letras!
} 
mundial como veículo de comunicação internacional, especialmente no comércio; a terceira língua internacional de política, diplomacia, economia e cultura (DIOGO, 2013).

A demanda brasileira por cursos de espanhol reflete a necessidade anunciada de fortalecer os cursos de formação de professores, especialmente os de graduação em Letras/Espanhol. Para situar um pouco os nossos leitores, a Agencia EFE Madrid ${ }^{4}$ divulgou em 2015 que, no mundo todo, 21 milhões de pessoas estudam espanhol como língua estrangeira, o que representa um aumento de quase 1,5 milhão com relação a 2014. Os números comprovam que a busca pelos cursos de Espanhol é crescente e os motivos diversos, daí a necessidade de investir nos cursos de Licenciatura letras/Espanhol.

Trabalhar o ensino de E/LE no curso de Letras/Espanhol, na perspectiva crítica é assumir o papel ativo na formação dos futuros professores. Acolhendo o pensamento de Miranda Poza (2012, p. 341):

(...) el alumno de un curso de letras, no sólo debe limitarse a "saber español", esto es, a alcanzar un determinado nivel de conocimiento (inicial, medio, avanzado, superior, etc.), sino que, además, debe profundizar en ese conocimiento, lo que implica un estudio reflexivo sobre la lengua, sobre el español, de forma paralela a lo que ocurre en vernáculo: no vale solo con "saber hablar portugués" (todos los alumnos brasileños lo saben mucho antes de entrar en la universidad), sino que se exigen otros muchos conocimientos complementarios considerados indispensables para poder llegar a ser considerado un "profesor de portugués". 5

Não sou meramente observadora ou pesquisadora passiva, sou pedagoga crítica e almejo transformar a realidade da nossa comunidade acadêmica.

Por esta razão, esta pesquisa contribui favoravelmente no campo da formação dos futuros professores de espanhol, pautados em uma abordagem de ensino que trate as questões da linguagem de forma crítico-colaborativo e com uma práxis que contempla os aspectos sóciohistóricos-culturais da Educação Brasileira, por meio da elaboração, implementação, avaliação e reconstrução do plano de aula, a partir da experiência colaborativa em todos os momentos, de ter dado aula de verdade.

A elaboração colaborativa de aulas a serem ministradas pelos futuros professores de língua espanhola resgata a participação sócio-histórico-cultural dos sujeitos inseridos neste processo e viabiliza a enunciação numa relação estreita com a língua/linguagem, em que os enunciados são constituintes dos discursos e estes, por sua vez, conformam a natureza das relações e das formas de atuação do homem no mundo. Posso mesmo afirmar, que a nossa comunhão com as visões de língua na perspectiva sócio-histórico-cultural, consolida a nossa práxis docente nas inter-relações sociais com os nossos alunos, na elaboração dos planos de aula e no desenvolvimento das atividades de ensino da língua espanhola, ao longo do Estágio Colaborativo.

\footnotetext{
4 Disponível em: https://www.efe.com/efe/brasil/educacao/relatorio-aponta-que-21-milh-es-de-pessoas-nomundo-estudam-espanhol/50000242-2644258
}

\footnotetext{
${ }^{5}$ Tradução livre do Espanhol para o Português: (...) o aluno de um curso de letras, não deve limitar-se apenas a "saber espanhol", isto é, a alcançar um determinado nível de conhecimento (inicial, médio, avançado, superior, etc.), mas, além disso, deve aprofundar-se nesse conhecimento, o que implica um estudo reflexivo sobre a língua, sobre o espanhol, de forma paralela ao que ocorre em vernáculo: não vale só o "saber falar português" (todos os alunos brasileiros o sabem muito antes de entrar na universidade), e sim, que se exijam outros conhecimentos complementares considerados indispensáveis para poder chegar a ser considerado um "professor de português".
} 


\section{A formação de professores de línguas estrangeiras e a sua performance no estágio supervisionado}

A elaboração colaborativa de aulas a serem ministradas pelos futuros professores de língua espanhola resgata a participação sócio-histórico-cultural dos sujeitos inseridos neste processo e viabiliza a enunciação numa relação estreita com a língua/linguagem, em que os enunciados são constituintes dos discursos e estes, por sua vez, conformam a natureza das relações e das formas de atuação do homem no mundo. Podemos mesmo afirmar, que a nossa comunhão com as visões de língua na perspectiva bakhtiniana, consolida a nossa práxis docente nas inter-relações sociais com os nossos alunos e no desenvolvimento das atividades de ensino da língua espanhola, ao longo do Estágio Supervisionado (DIOGO, 2014).

A demanda brasileira por cursos de espanhol reflete a necessidade anunciada de fortalecer os cursos de formação de professores, especialmente os de graduação em Letras/Espanhol. Trabalhar o ensino de E/LE no curso de Letras/Espanhol, na perspectiva crítica é assumir o papel ativo na formação dos futuros professores. Acolhendo o pensamento de Miranda Poza (2012, p. 341):

(...) el alumno de un curso de letras, no sólo debe limitarse a "saber español", esto es, a alcanzar un determinado nivel de conocimiento (inicial, medio, avanzado, superior, etc.), sino que, además, debe profundizar en ese conocimiento, lo que implica un estudio reflexivo sobre la lengua, sobre el español, de forma paralela a lo que ocurre en vernáculo: no vale solo con "saber hablar portugués" (todos los alumnos brasileños lo saben mucho antes de entrar en la universidad), sino que se exigen otros muchos conocimientos complementarios considerados indispensables para poder llegar a ser considerado un "profesor de portugués".

Corroborando a tese de Miranda Poza, a nossa proposta ao adotar o ensino da língua espanhola na visão da TASHC - Teoria da Atividade Sócio-Histórico-Cultural, que "focaliza o estudo das atividades em que os sujeitos estão em interação com outros em contextos culturais determinados e historicamente dependentes", Liberali, (2009). Assim a nossa proposta está apoiada no ensino das línguas estrangeiras, pensado para que o aluno da graduação Letras/Espanhol, atue como aluno-pesquisador ao mesmo tempo em que a nossa atuação docente propicie instrumentos e artefatos que garantam o protagonismo discente, (DIOGO, 2013). Por esta razão, esta pesquisa contribui favoravelmente no campo da formação dos futuros professores de espanhol, pautados em uma abordagem de ensino que trate as questões da linguagem de forma crítico-reflexiva e com uma práxis que contempla os aspectos sócio-históricos-culturais da Educação Brasileira.

\section{Vozes Teóricas Convidadas à Argumentação Colaborativa}

[...] devo entrar em empatia com esse outro indivíduo, ver axiologicamente o mundo de dentro dele tal qual ele o vê, colocar-me no lugar dele e, depois de ter retornado ao meu lugar, completar o horizonte dele com o excedente de visão que desse meu lugar se descortina fora dele.

\section{$B A K H T I N$}

A concepção de uma pesquisa de caráter intervencionista, reflexivo-crítico-colaborativo, (LIBERALI e LIBERALI, 2005), contempla a língua/linguagem numa perspectiva dialógica. Assim sendo, a visão de língua que aqui adotamos é a que a postula no conjunto dos aspectos históricos, profundamente sociais e carregada de ideologias. "A palavra está sempre carregada de um conteúdo ou de um sentido ideológico ou vivenvial”, (BAKHTIN/ VOLOCHINOV, 1997, pg. 95). Ao defendermos a língua como ideológica, na sua constituição sócio-histórico-cultural, nos inserimos no contexto enquanto sujeitos sócio-histórico-culturalmente constituídos dos discursos diversos do nosso cotidiano (DIOGO, 2013). 
Consideramos os aportes da forma linguística como coadjuvantes no processo da comunicação enunciativa precisa, por isso mesmo imbricada pelo contexto ideológico. Para corroborar esta tese, Bakhtin (1997), ressalta:

Toda enunciação, mesmo na forma imobilizada da escrita, é uma resposta a alguma coisa e é construída como tal. Não passa de um elo da cadeia dos atos de fala. Toda inscrição prolonga aquelas que a precederam, trava uma polêmica com elas, conta com as reações ativas da compreensão, antecipa-as. (...) Uma inscrição, como toda enunciação monológica, é produzida para ser compreendida, é orientada para uma leitura no contexto da vida científica ou da realidade literária do momento, isto é, no contexto do processo ideológico do qual ela é parte integrante. (BAKHTIN/ VOLOCHINOV, 1997, pg. 98).

A presente pesquisa tem ainda como aporte teórico a TASHC - Teoria da Atividade SócioHistórico-Cultural. Referenciando Vygotsky, Leontiev e Bakhtin, Liberali (2009, p. 19), elucida:

$\mathrm{Na}$ perspectiva sócio-histórico-cultural, os sujeitos constituem-se e aos demais nas relações com os objetos/mundo mediados pela sociedade. Esse processo de constituição de si, dos demais e da própria sociedade é de fundamental importância ao considerarmos a formação crítica de educadores. Para Vygotsky (1934), em suas práticas sociais, os sujeitos se engajam em atividades distintas e são essas atividades que propiciam oportunidades de desenvolvimento de si, dos outros e da sociedade.

Essas elucidações sobre a Teoria da Atividade Sócio-Histórico-Cultural, doravante TASHC, posicionam a nossa atuação na esfera do ensino-aprendizagem da língua espanhola, pois defendemos o paradigma de ensino onde professores e alunos vão se constituindo colaborativamente, por meio das atividades sociais que a comunidade acadêmica, no nosso caso, da graduação em Letras/Espanhol, demanda. Os princípios da Teoria da Atividade SócioHistórico-Cultural - TASHC, que serão tomados em consideração na intervenção colaborativa do gênero elaboração de aula serão os sistemas de atividades situados, sentidos e significados.

A argumentação constitutiva dos saberes da sala de aula aporta valores de relevante significação para a presente pesquisa. Nesse sentido, nos apoiamos em (DAMIANOVIC, 2010), quando elucida que:

Nas suas atividades, as pessoas mudam constantemente e criam novos objetos. Neste processo, o futuro é forjado política e afetivamente em ações, decisões e esforços de mudanças discursivas. Os objetos geram oposições e controvérsias capazes de potencializar a escala de influência global porque são emancipatórios a ponto de abrir novas possibilidades de desenvolvimento e bem estar.

A organização argumentativa é essencial na produção de entendimentos colaborativos da realidade, (LIBERALI, 2011). Existe aqui uma revisão de ideias que vai sendo construída nesse processo colaborativo e a visão inicial dos interlocutores é gradualmente modificada. Uma importante contribuição para os estudos da organização argumentativa na sustentação da presente pesquisa está nos postulados de (LEITÃO, 2000):

Nos contextos argumentativos de aprendizagem, a ideia é que argumentar não necessariamente significaria uma forma de ceder e aceitar um ponto de vista, e sim como um método pelo qual é possível reconstruir visões e alcançar, de forma mais flexível, uma melhor abordagem de diferentes perspectivas para lidar com uma situação focal que envolva mudanças conceituais.

Corroborando a tese de Leitão, (2000), o presente estudo defende o aspecto argumentativo no processo de elaboração do plano de aula de língua espanhola com especial foco nas atividades sociais demandadas pelos sujeitos envolvidos nessa trajetória do ensino e da aprendizagem. 


\section{Reflexões metodológicas}

O estudo em pauta está inserido nas abordagens da Pesquisa Crítica de Colaboração, Magalhães (2006) e Magalhães; Oliveira (2011), por ser uma investigação crítico-reflexiva, norteada pela professora-pesquisadora quando da observação da sua própria ação e a dos seus alunos. Apoiados nos postulados de Magalhães e Oliveira (2009, p.3), destacamos a relevância do trabalho docente fundamentado na PCCol (Pesquisa Crítica de Colaboração):

(...) a colaboração crítica se refere à práxis do docente em seu contexto sócio-histórico e cultural, na relação com os outros, à maneira como ele compreende sua atuação e os motivos que regem sua prática social e a construção da prática educativa.

Corroboramos a tese de Magalhães e Oliveira (2009, p. 01), quando aportam "a colaboração crítica como categoria, enfatizando o movimento de constituição dos sujeitos no desenvolvimento da atividade docente, que se revela em um modo de agir a partir de uma complexa rede de mediações nos relacionamentos em processo, relacionamentos esses que constituem o ser social".

Esta pesquisa está inserida nos pressupostos da TASHC (Teoria da Atividade SócioHistórico-Cultural), (LIBERALI, 2009), para a qual os sujeitos se constituem na colaboração mútua e é nesse contexto que a nossa práxis está inscrita, ou seja, no sócio-histórico e cultural na relação com os alunos, futuros professores da língua espanhola. Tomando como base a teoria enunciativa de Bakhtin será analisada a inserção de vozes enunciativas no processo de compreensão de sentidos e de identidades profissionais, através da gravação em áudio das reuniões de planejamento e da escrita dos planos de aula.

A necessidade de atribuir sentido à elaboração dos planos de aulas na disciplina estágio supervisionado, no $6^{\circ}$ período da graduação Letras/Espanhol, percebida ao longo do processo do estágio, fortalece e justifica a presente pesquisa no âmbito da TASHC e da pesquisa críticocolaborativa. Os dados foram coletados nos Fóruns de Estudo do GEACLE- Grupo de Estudios Argumentativos Crítico-Colaborativos en Lengua Española, ocorridos nas escolas-campo e na Faculdade Luso-Brasileira, durante o processo de elaboração de aulas na fase da regência do Estágio Supervisionado, no período de agosto a dezembro/2015, após aprovação do CEP/UFPE.

\section{Análise parcial dos dados}

Os primeiros dados da presente pesquisa nos revelam que as reuniões sistematizadas de elaboração de aulas de forma colaborativa na etapa da regência no Estágio Supervisionado, reposicionam os discentes à medida que o papel da argumentação é fortalecido e incorporado nessas ocasiões. Foram realizadas inicialmente três reuniões com três grupos de estagiários e os argumentos utilizados, mesmo quando observadas discordâncias, demonstram um salto qualitativo na elaboração das aulas.

A discussão colaborativa dos elementos constituintes dos planos de aulas, a seleção das atividades, dos textos, dos áudios, dos vídeos a serem trabalhados com os alunos das escolascampo, intensificam as vozes enunciativas dos alunos e lhes dá maior segurança quanto à sua performance no momento em que têm a função de regentes.

Os procedimentos de produção, coleta, discussão e armazenamento de dados estão em consonância com as exigências do CEP (Conselho Ético de Pesquisa) da Universidade federal de Pernambuco. Todos os dados se encontram no banco de dados do Grupo de Pesquisa LIGUE (Língua, Linguagens, Escola e Ensino), da UFPE, coordenado pela Professora Dra Maria Cristina Damianovic.

Nossos achados foram se descortinando a partir das necessidades visualizadas pelos participantes da pesquisa, alunos do $6^{\circ}$ período de Letras da FALUB (Faculdade Luso-Brasileira). Para elencar as necessidades dos alunos das escolas apareceu mais um sujeito: os alunos das escolas campo (AEC), onde os alunos estagiários (AE) realizaram as observações e regência. Trabalhamos 
com áudio, vídeo, elaboração de material didático, questionário online e fóruns de discussão críticocolaborativa.

\section{Excerto 1}

Questionários utilizados para iniciar o levantamento dos temas e das atividades sociais no plano de aula:

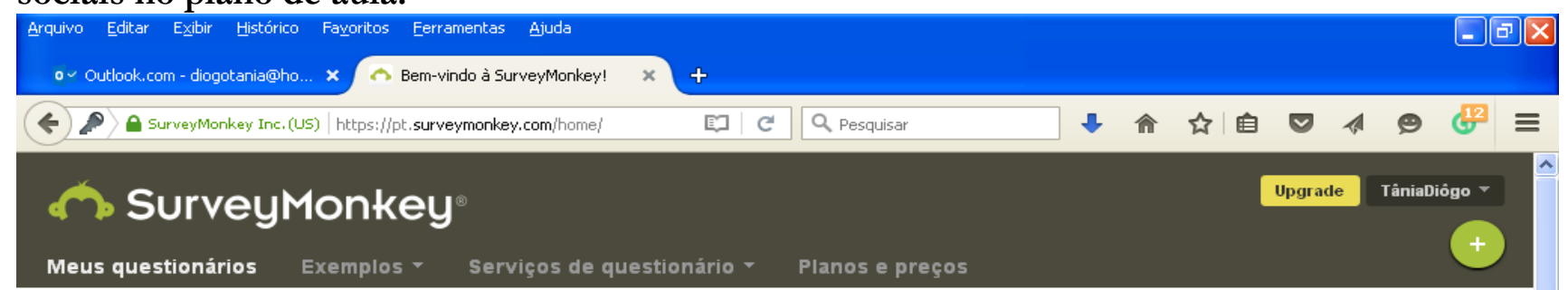

\begin{tabular}{|c|c|c|c|c|c|}
\hline TODOS OS QUESTIONÁRIOS & $\checkmark$ & $\boldsymbol{a}$ & & & \\
\hline ті́тULо & & MODIFICADO - & RESPOSTAS & AçÖES & \\
\hline $\begin{array}{l}\text { ¿Serias tan amable en hablar un poco } \\
\text { sobre ti? } \\
\text { Criado em } 3 / 09 / 2015\end{array}$ & & $19 / 11 / 2015$ & 3 & ك & - \\
\hline $\begin{array}{l}\text { Necesidades y Metas de Enseïanza y } \\
\text { Aprendizaje } \\
\text { Criado em 3/09/2015 }\end{array}$ & & $15 / 09 / 2015$ & 2 & [4 & - \\
\hline $\begin{array}{l}\text { Por favor, háblanos un poco más } \\
\text { sobre ti: } \\
\text { Criado em 3,09/2015 }\end{array}$ & & $15 / 09 / 2015$ & 1 & [ك 218 Wl & - \\
\hline $\begin{array}{l}\text { Encuesta Nuestro Entorno } \\
\text { Criado en 3/09/2015 }\end{array}$ & & $15 / 09 / 2015$ & 2 & 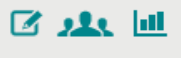 & - \\
\hline + Criar questionário & & & & & \\
\hline
\end{tabular}

SurveyMonkey em qualquer lugar

Crie questionários e monitore os resultados no seu aplicativo móvel todos os dias, a qualquer hora. Grátis para iOS e Android.

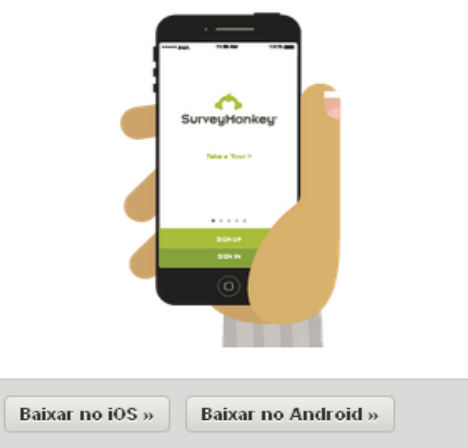

Obtenha ajuda com questionários, ideias e dicas

Aprenda a criar um questionário como um profissional

Disponível em: https://pt.surveymonkey.com/home/

Acesso em: 28/02/2016 


\title{
Excerto 2
}

Primeira versão do primeiro plano de aula

\author{
Plan de clase \\ Clases 1- 2 -3 \\ Tema \\ Hombre $\times$ Trabajo \\ Objetivos \\ Hacer un debate sobre la relación entre el hombre y el trabajo. \\ Destrezas Comunicativas \\ La producción oral; \\ La comprensión auditiva. \\ Contenido a ser trabajado \\ El curta metraje - El empleo de Santiago Bou Grasso y \\ Lectura de un texto donde habla sobre la definición de la palabra trabajo. \\ Recursos didácticos \\ Televisión y notebook. \\ Evaluación \\ El objetivo es dividir el grupo en dos equipos donde uno habla sobre la \\ importancia del trabajo enla vida de las personas y el otro sobre las \\ consecuencias de ello. \\ * El trabajo dignifica el hombre o es un instrumento de tortura? \\ Carga horaria \\ De una hora a una hora y media para cada clase.

\section{Links} \\ https://www.youtube.com/watch? ${ }_{v}={ }_{c x} U u U 1 j w M g M$
}

A primeira versão do plano de aula sinaliza ainda uma forte estruturação na forma do gênero, sem levar em consideração as questões discursivas e a relevância argumentativa. A argumentação colaborativa nesse cenário é fundamentalmente pertinente para garantir uma práxis centrada na reflexão e na construção das múltiplas aprendizagens dos futuros professores de línguas estrangeiras, com foco na elaboração dos planos de aula.

\section{CONSIDERAÇÕES FINAIS}

Os nossos estudos iniciais no campo da Argumentação colaborativa corroboram a tese que inserem as vozes enunciativas na formação inicial em Letras na disciplina de Estágio Supervisionado. Adotar uma práxis crítico-reflexiva e criativa na perspectiva da TASHC consolida o reposicionamento social dos discentes e possibilita a inserção de suas vozes na transformação de uma práxis que liberte e que permita desdobramentos futuros no Curso de Letras e no ensino das línguas estrangeiras. Os alunos aprendem muito mais e com melhor qualidade quando constroem o conhecimento em sala de aula, atribuindo-lhe novos valores, sentidos e significados, a partir da mediação do professor, de outros colegas e da sua performance que lhe permite "ir mais além de si mesmo como outro", Liberali (2009). A Argumentação colaborativa nesse sentido, ao inserir as vozes enunciativas dos discentes no processo do Estágio Supervisionado, por ocasião das reuniões de elaboração de aulas, consolidam o processo dialético na etapa da regência. 


\section{REFERÊNCIAS}

BAKHTIN, M.; VOLOCHÍNOV, V. N. (1929-30). Marxismo e filosofia da linguagem. Tradução de Michel Lahud e Yara Frateschi Vieira. 14a. Ed. São Paulo: Hucitec, 2010.

BAKHTIN, M. 1992. Estética da Criação Verbal. 3a ed. São Paulo:

Martins Fontes, 2000.

DAMINOVIC, M. C. O linguista aplicado: de um aplicador de saberes a ativista político. Revista Linguagem \& Ensino. Pelotas, v. 8, n. 2, p. 181-196, jul./ dez. 2005.

DIOGO, Tânia Maria. O ensino-aprendizagem da língua espanhola através da atividade social escrita de resumos para apresentação de pôster em congresso: o protagonismo discente na graduação em Letras. Dissertação de Mestrado.UFPE/PPGLetras. Recife, pp. 216

LIBERALI, F.C. Formação Crítica de Educadores: Questões Fundamentais. Coleção Novas Perspectivas em Linguística Aplicada.Vol. 8. Campinas, SP: Pontes Editores, 2010.

LEITÃO, Selma. - DAMIANOVIC, Maria Cristina. (Org.). Argumentação na escola: o conhecimento em construção. Campinas, SP: Pontes Editores, 2011.

MAGALHÃES, M. C. C (Org.) A formação do professor como profissional critico: linguagem e reflexão. Campinas: Mercado de Letras, 2004.

MEDRADO \& REICHMANN, (Orgs.). Projetos e Práticas na Formação de Professores de Língua Inglesa. João Pessoa: Editora da UFPB, 2012.

MIRANDA POZA, J.A. La universidad ante los desafíos de la enseñanza de español en Brasil.

EUTOMIA, revista de Literatura e Linguística. UFPE. Edição 10, Recife, dezembro 2012.

RAJAGOPALAN, Kanavillil. Por uma linguística crítica: linguagem, identidade e a questão ética. São Paulo: Parábola Editorial, 2003.

Recebido em 01/03/2017

Aceito em 08/07/2017

Publicado em 06/02/2018 